\title{
Implicitness, Logical Form and Arguments
}

\author{
MARTINA BLEČIĆ \\ University od Rijeka, Rijeka, Croatia
}

In the paper I suggest that a loose notion of logical form can be a useful tool for the understanding or evaluation of everyday language and the explicit and implicit content of communication. Reconciling ordinary language and logic provides formal guidelines for rational communication, giving strength and order to ordinary communication and content to logical schemas. The starting point of the paper is the idea that the bearers of logical form are not natural language sentences, but what we communicate with them, that is, their content in a particular context. On the basis of that idea, I propose that we can ascribe logical proprieties to what is communicated using ordinary language and suggest a continuum between semantic phenomena such as explicatures and pragmatic communicational strategies such as (particularized) conversational implicatures, which challenges the idea that an implicatum is completely separate from what is said. I believe that this continuum can be best explained by the notion of logical form, taken as a propriety of sentences relative to particular interpretations.

Keywords: Logical form; impliciture; conversational implicatures; context.

\section{Introduction}

Philosophers have always been interested in the patterns of correct reasoning, that is, in what differentiates valid from invalid inferences. The idea was that good reasoning shows patterns that can be schematically characterized by abstracting from the specific content of the involved premises and conclusions, thus revealing a general form com- 
mon to many other good inferences. Arguments constructed following these schemas are considered valid. A significant complication is that the context is important in ordinary language as to which proposition is expressed by a particular sentence. Still, ordinary language and correct reasoning are interconnected, and it is hard to talk of one without the other or to reduce correct reasoning to abstract schemas for which content and context are irrelevant. Doing so seems like engaging in a logical game devoid of any real-life implications. Perhaps this is one of the reasons there are two senses in which we use the term "logical form"-one is logical and the other is linguistic. Still, the two are sometimes used interchangeably, which poses the question of whether there is a unified account of logical form.

In this paper, I will use the idea, proposed by A. Iacona, that the bearers of logical form are not natural language sentences, but what we communicate with them, that is, their content in a particular context. This means that we can ascribe logical proprieties to what is communicated in real-life situations, using ordinary language. I will use this idea to propose a continuum between phenomena such as explicatures, in which the content of an utterance is assessed in relation to the context and the speaker, even when language is used directly and literally, and indirect and implicit communicational strategies such as (particularized) conversational implicatures. Sometimes, sentences will need a contextual supplement to express a full proposition or the specific content the speaker has in mind. This expanded sentence can then be evaluated for its truth or falsity. All of this happens on the level of explicit communication. On the implicit level, we can also provide supplements to what is said to reach the message intended by the speaker, but in this case, it will not amount only to a few words, but entire additional premises will be needed to reach the intended conclusion. I present the idea that we can look at (particularized) conversational implicatures as arguments in which the speaker provides reasons for the conclusion and does not expect an answer from the interlocutor. They are also distinguished from other forms of arguments by the fact that only one premise is explicitly expressed in them, and the conclusion (the content of the implicature, the so-called implicatum) is built jointly by the speaker and the hearer in a given conversational situation. I suggest that this shows that a loose notion of logical form can be a useful tool for assessing or evaluating everyday language, from explicit to implicit sentences. Reconciling ordinary language and logic provides formal guidelines for rational communication, giving a sense of order to ordinary communication and content to logical schemas.

\section{Logical form}

When we talk about logical form, we can have in mind two applications of the term. The first one is related to logic, where we use the notion of logical form, for example, to evaluate the validity of arguments. The 
second one is said to underlie the structure of sentences and it is used in theories of meaning.

The beginnings of the study of logical form are found in the observation of patterns of inference that can be determined through the schematization of certain expressions. Aristotle, the Stoics and medieval logicians used paraphrases of natural language sentences made with the tools provided by the same language, but which aimed to emphasize patterns of correct reasoning (for example: All A are Bs, All Cs are A: All Cs are B). Much later, philosophers such as Frege, Wittgenstein and Russell aimed to clarify the logical properties of a natural language sentence by formalization in the perfect language of logic, using formal quantifiers and logical connectives ${ }^{1}$. A basic feature of a logically perfect language, which makes it different from natural language, is the following: every sentence has definite truth-conditions that are determined by its semantic structure and reflected in its syntactic structure (Iacona 2018: 22).

Natural language cannot satisfy this requirement. Just think of features of natural language like vagueness ("Jack is bold"), ambiguity ("Jack is going to the bank") or context sensitivity ("Jack is here"). Frege (1879, 1891), Russell (1905, 1984, 1998), and Wittgenstein (1992, 1993) shared three main claims about logical form: logical properties depend on logical form; logical form may not be visible in surface structure, and logical form is exhibited in a logically perfect language. They did not regard natural language as intrinsically interesting; they believed that natural language is incapable of being studied rigorously and systematically. This attitude towards natural language prevailed until the middle of the twentieth century. A first step in the opposite direction was prompted by the program of generative grammar in the 1950s when N. Chomsky $(1976,1995)$ proposed the idea of a Universal Grammar, a system of syntactic rules that underlies all natural languages. The next big step was the idea of compositionality proposed by Frege and Davidson. The idea is fairly simple: since the language has a finite vocabulary but an infinite number of sentences, it must be assumed that the meaning of a sentence depends on the meanings of its parts. According to Davidson's account, to give the logical form of a sentence is to describe its semantically relevant features against the background of a theory of truth. The central idea of Davidson's program is that meaning is a matter of truth conditions: to know the meaning of $s$ is to know the conditions under which $s$ is true: „Snijeg je bijel" is true if and only if snow is white: "What should we ask of an adequate account of the logical form of a sentence? Above all, I would say, such an account must lead us to see the semantic character of the sentence - its truth or falsity-as owed to how it is composed, by a finite number of applications of some of a finite number of devices that suffice for the language as a whole, out of elements drawn from a finite

${ }^{1}$ For a good historical overview see Pietroski 2016. 
stock (the vocabulary) that suffices for the language as a whole. To see a sentence in this light is to see it in the light of a theory for its language, a theory that gives the form of every sentence in that language" (Davidson 1968: 131).

Later, Montague $(1970,1973)$ provided the first proper formal treatment of English based on Tarski's method. An important extension of Montague's methods concerns the treatment of indexicals and demonstratives, that is, context-sensitive expressions such as 'I', 'you', 'now', 'this', 'that' or 'there'. As suggested by Lewis (1970) and Kaplan (1977), a sentence containing indexes or demonstratives can be formally described as a sentence that has true conditions with respect to parameters, understood as sets of coordinates that provide appropriate semantic values for indexes or demonstratives appearing in the sentence. This is important because it shows that we can ascribe logical proprieties to highly contextual sentences.

Today, there is an additional element added to the conception of logical form proposed by Frege, Russell and Wittgenstein, creating this picture: logical properties depend on logical form, meaning depends on logical form, logical form may not be visible in surface structure, logical form is exhibited in a perspicuous language (see Iacona 2018: 35). Here, the logical view of logical form, which is concerned with the formal explanation of logical properties and logical relations, such as validity or contradiction and the semantic view, concerned with the formulation of a compositional theory of meaning, come together. Following Iacona, we can say that semantic theorists such as the beforementioned Davidson, Montague, Lewis and Kaplan, but also Neale (1993), Stanley (2000), and Borg (2007) share the assumption that the notion of logical form that appears in semantic theory is also able to explain the logical properties and relationships between sentences.

The question is whether the semantic notion of logical form can fulfill this logical role, for instance, when it comes to sentences involving context sensitivity. Iacona claims that it cannot. For example, consider the following simple example (Iacona 2018: 49). When you say "I am a philosopher" and I say "You are not a philosopher," in a particular context, our disagreement is not just about the difference between the way we judge the truth of each of those sentences. There is a logical relationship between them, namely, contradiction, so it cannot be the case that both sentences are simultaneously true. A semantic approach that ascribes a logical form to each sentence separately, and out of context, cannot explain the logical relations dependent on context. According to Iacona, we need a new notion of logical form. The bearers of logical form are not natural language sentences, but what we communicate with them, that is, their content in a particular context. Sometimes the logical form of a sentence will not be straightforward: "This means that there is no such thing as "the" logical form of a sentence. Sentences have logical form relative to interpretations, because they have logical form in virtue of the content they express" (Iacona 2018: 60). 
An interesting idea explored by Iacona is the question of the relation between form and expressions such as non-standard quantifiers or vague terms. Consider "More than half". The semantic theorist will deny that we can explain the validity of arguments involving these expressions in terms of logical form. But there is an intuitive sense in which such arguments are good because of their form. If there are four professors of philosophy in a certain department we would not be wrong if we take the sentence "more than half of the professors in the philosophy department are happy" to yield the conclusion "more than two professors in the philosophy department are happy". When there are only three professors in the philosophy department this conclusion would be false. Still, there would be some other inference that would seem valid. It would not be wrong to conclude "more than one professor in the philosophy department is happy". The goodness of each of these conclusions, it seems, depends on the form of what the sentences express. But since the semantic theorist ascribes the same logical form in all contexts to the sentence "more than half of the professors in the philosophy department are happy", she is unable to explain these conclusions as logical.

Iacona believes that such inferences are good by virtue of their logical form. According to him, even though "more than half of" is not firstorder definable, it is "first-order expressible" 2 . This means that in any interpretation the logical form of "more than half of the professors in the philosophy department are happy", can be captured by some firstorder formula that embodies all the relevant logical properties that the original sentence has in that interpretation. Thus, in any interpretation there would be some cardinal number, such that "more than half of the professors in the philosophy department are happy", is true in that interpretation for the intersection of the professor and the set of lucky ones which is greater than that number. This general fact explains why we have the intuition that "more than half of the professors in the philosophy department are happy", entails other sentences because of its logical form. Iacona concludes that there have to be two distinct notions of logical form, which are equally legitimate, but serve two distinct purposes.

Iacona's lesson for us will be that the bearers of logical form are not natural language sentences, but what we communicate with them; their content in a particular context. The most important idea is that sentences have a logical form relative to interpretations because they have a logical form in virtue of the content they express. His idea that there are logical proprieties hidden in sentences containing non-standard quantifiers will also be useful since it points to the possibility that

\footnotetext{
${ }^{2}$ Generalized quantifiers have been studied extensively, see for example Barwise and Cooper (1981), Clark (2011), Keenan and Paperno (2012) and for an overview see Westerståhl (2019).
} 
there is much logically describable content to be discovered in everyday communication. ${ }^{3}$

\section{Explicit and implicit communication}

Now we ask what is the relation between the content expressed by a sentence and the form that leads correct reasoning? Can we reduce semantics to syntax by providing a logical form for every natural language sentence as Davidson wanted? We will follow Soames (1989) in the idea that truth-functional semantics cannot explain understanding and that it is the wrong way to study semantics. But how do we proceed from here? What is the relation between meaning and context? Consider the sentence "It's raining“. What proposition is expressed here? Where does it rain, and is this information important? According to Bach (2014), this sentence does not express a complete proposition, and for Recanati (2004) there is a hidden indexical that specifies the location ("in X"). The options are many. Now we will briefly explore some of them.

According to Carston (2002), the gap between the coded sentence and what is said is a fundamental feature of natural language. Consider the sentence "The pot is black". We do understand it, but can we say what is expressed by it? In which sense is the pot "black"? Is it dirty, burnt, or made from a black material? To get to this sentence's concrete content, we need to explicate it.

According to Carston, the sentence is not the truth-bearer, this role is played by the proposition that is expressed by the speaker's utterance. And this proposition is called explicature. Here is how she explains the simple sentence "She hasn't called":

On any normal occasion of use, this will be understood as expressing a complete proposition in which it is predicated of a particular female that it is not the case that she has called (in some specific sense of 'call') some other particular person within some relevantly delimited time span up to the time of utterance. However, the sentence form itself encodes something much less specific, a non-propositional (non-truth-evaluable) logico-conceptual

${ }^{3}$ The idea that logical form is contextual lead some authors to be vary of the use of the term. As Dutilh Novaes writes: “(..) psychologists typically rely on a fairly naive understanding of the concept: the logical form of a sentence or argument would straightforwardly be 'read off' from its surface structure. But, at least since Russell, most philosophers are well aware of the fact that the 'logical form' of a sentence, if there is indeed such a thing, is often not straightforwardly correlated with its surface, grammatical structure. More importantly, what the experiments with the postal conditional illustrate is that logical form is not something that a sentence or argument has, in an independent, quasi-metaphysical sense; rather, logical form is at best something that speakers attribute to sentences or arguments by means of an interpretation. (...) I maintain that it is best simply to stop using the concept of 'logical form' as a property of sentences and arguments. Even understood as something that is attributed to sentences and arguments by speakers, the concept evokes too many infelicitous connotations. Rather, it seems more appropriate to speak more generally of the semantic interpretation given to a sentence by a speaker, so as to avoid conceptual muddle" (Dutilh Novaes 2012: 122). 
structure, an 'assumption schema', which functions as a template for the construction of fully propositional (truth-evaluable) logico-conceptual structures. It is this schematic logical form that the initial (purely linguistic) phase of understanding delivers and which is the input to the pragmatic processes aimed at constructing the propositional form intended by the speaker, or one similar enough to it to have the intended effects. (Carston 2002: 59)

But explicatures are not the only enrichment option for a sentence, there are also Gricean conversational implicatures. We can illustrate the difference between the two with the beforementioned pot example. The sentence we consider is "The pot is black", a possible explicature is the content that the pot is burnt. A possible implicature, derived from this particular explicature is: "Use another one". Both explicatures and implicatures depend on the intention of the speaker, but there are differences. According to Carston: "An assumption (proposition) communicated by an utterance is an 'explicature' of the utterance if and only if it is a development of (a) a linguistically encoded logical form of the utterance, or of (b) a sentential subpart of a logical form" (2002: 124). As Carston states it: "the Gricean schema for figuring out a speaker's conversational implicature(s) from what she has said is a pure piece of (...) personal-level practical belief/desire reasoning; it is conscious, rational and normative" (2002: 7). Explicatures are to be found in every sentence, which is not the case with implicatures. We can say that explicatures are necessary, and conversational implicatures are optional in the sense that the same sentence on certain occasions carries with its utterance an implicature and doesn't' carry it in others. F. Recanati has argued for two quite distinct kinds of pragmatic processes, subpropositional associative primary processes, driven solely by cognitive effort considerations, and properly inferential propositional secondary processes, guided by the standard Gricean maxims and not explainable at a sub-personal computational level. Theories along the lines of this idea have been called dual pragmatic theories. According to these theories, pragmatic processes are capable of acting twice: once before the delivery of a complete proposition expressed (that is, before determining the truth-conditional content of the sentence as uttered in a given context) and then once again to yield any implicatures of the utterance (i.e. any further, indirectly conveyed, propositions).

But not all theorists agree with this contextual conception of semantics. According to Borg, the answer to a better understanding of semantic meaning lies in what is called minimal semantics:

A minimal semantic theory, on my terms, is a theory which seeks to give the literal meaning of types of words and sentence-types (relativized to a context of utterance) in a given natural language, and that's pretty much it. Specifically, such a theory keeps its nose out of a range of related explananda, such as how we succeed in communicating with one another using language, how we come to know about objects in the world around us, and, in general, how properly linguistic information comes to interact with the vast range of other information an agent possesses. (Borg 2004: 54) 
According to Borg, what lies within reach of our formal semantic theory must involve only those features which can be recovered by simple deductive operations on the syntactic content of a sentence, "nothing which requires abductive reasoning (like mindreading) can be treated as a proper part of the semantic theory. So the semantics/pragmatics divide becomes a division between information in, or generated by, our purely formal, computational language faculty and information in, or generated by, other cognitive domains" (Borg 2004: 261).

As opposed to the contextualist idea that context is necessary to determine the content of a sentence, proponents of minimal semantics believe that syntactical features are enough to provide us with a proposition. According to them, we can determine the proposition expressed by every sentence in this formal way. But consider the sentence "Ann cannot continue", what proposition, out of any context, does it express? As I mentioned earlier, Bach believes that in some situations, sentences just do not express propositions, at least not on a purely sintacticosemantic level. Bach proposes the notion of conversational impliciture, which he considers to be closely related, but not the same as explicature $^{4}$. He distinguishes two types of impliciture, depending on whether the hearer must do some conceptual filling in of a propositional radical or fleshing out of a minimal proposition to ascertain what the speaker means. For example, sentences like "Steel isn't strong enough" or "Willie almost robbed a bank", "though syntactically well-formed, are semantically or conceptually incomplete, in the sense that something must be added for the sentence to express a complete and determinate proposition (something capable of being true or false)" (Bach 1994: 127). On the other hand, sentences like "You're not going to die" and "I have eaten breakfast" require a degree of completion, not because they do not express a proposition, they do, but this proposition is not what is communicated by the speaker. "You are not going to die" said to a child with a cut finger does not mean that the child is immortal, but that she is not going to die from that particular cut. Likewise, someone saying that they did not have breakfast is probably not saying that they never ate breakfast.

This idea that in order to get to a complete proposition, even at the explicit level of communication we need to establish what is being communicated is in accordance with Iacona's view of logical form. Once we have, with the use of pragmatic additions, determined the content of a particular sentence, we can explore the logical form underneath it.

\section{Explicit and implicit: A matter of degree}

Levinson (2000) had discussed the relationship between logical form and implicatures. According to him, the Gricean notion of "what is said", which is the proposition expressed by the use of a sentence or the truth-conditional content of the utterance, that depends on reference

${ }^{4}$ See Bach (2010). 
resolution, indexical fixing, and disambiguation, is too restricted. He points out that "implicatures can be seen paradoxically to play a role in the establishment of what is said" (Levinson 2002: 172). It is important to note that Levinson is focused on generalized conversational implicatures, that can fall within the scope of logical operators and other higher-level processes of semantic composition. A generalized implicature is a conversational implicature that is inferable without reference to a special context. Expressions with the form an X usually imply that $\mathrm{X}$ is not closely related to the speaker or subject, as in "John walked into a house yesterday". This expression implies that the house is not John's house. In this paper, I tried to broaden the role of conversational implicatures in the discussion of logical form focusing on particularized conversational implicatures, for which context is crucial, but their interpretation is still governed by patterns of correct reasoning.

I will now return to the differences between conversational implicatures and explicatures and/or implicitures. The idea is that there is a sharp distinction between the fleshed-out logical form attributed to an utterance, that is, its explicature, and fully implicit, pragmatically conveyed propositions, that is, implicatures (see Sperber and Wilson 1986: 181, 182). When we consider sentences like "It is raining", to get to a content that we can assess as true or false, we will have to specify the location we have in mind since we do not want to convey the information that it is raining somewhere, in an unspecified part of the word (or even further). This information is, in this sense, necessary. This is an impliciture, for some authors, and for others, it is an explicature. Besides, there are other communicational layers the speaker could wish to convey to the hearer. For example, if the utterance of "It's raining" is a response to the question "Have you mowed the grass?" then it would mean something like: "No, I didn't mow the grass (because it's raining)". This is a clear case of conversational implicature. For the hearer to reach the intended message there must be an adequate connection between what is said/explicated and what is implicated. Even though this should not be problematic, it seems that some formulations of the distinction between explicatures/implicitures and implicatures point to a complete separation between the implicature and the syntacticosemantic layer of the sentence. ${ }^{5}$ Consider how Bach presents the distinction between implicitures and implicatures:

An implicatum is completely separate from what is said and is inferred from it (more precisely, from the saying of it). What is said is one proposition and what is communicated in addition to that is a conceptually independent proposition, a proposition with perhaps no constituents in common with what is said. (...) In contrast, implicitures are built up from the explicit content of the utterance by conceptual strengthening or what Sperber and

5 Levinson (2000) presents six criteria that are used for distinguishing explicatures from implicatures and rejects all of them and claims that they "fail to make any clear distinction between explicature and implicature" (196). Again, it should be noted that Levinson focuses on generalizes conversational implicatures. 
Wilson (1986) call 'enrichment', which yields what would have been made fully explicit if the appropriate lexical material had been included in the utterance. Implicitures are, as the name suggests, implicit in what is said, whereas implicatures are implied by (the saying of) what is said." (Bach 1994: 141)

Bach explicitly states that implicatures are completely separate from what is said. According to him, what is communicated is a proposition conceptually independent from what is said, so different from it that it does not need to have any constituents in common with it. This seems like a position that could make the understanding of implicatures seem like a mysterious process. Returning to our previous example, if the implicature in question is "I didn't mow the grass" then there must be a connection between the initial sentence "It is raining", its impliciture "It is raining in Rijeka" and its implicature. In order for a person to be able to conclude that her interlocutor did not mow the grass, she must be able to correctly link what was said and the implicature-there has to be a meaningful connection. This connection is not some just abstract relation between these communicational levels, it is a relation that can, at least to a certain extent, be formalized. To properly understand an implicature, its reconstruction will have to start at the semantic level. During this process, the initial constituents will be used in such a way to lead to the desired communicational outcome. That means that the difference between implicitures (or explicatures) and conversational implicatures is not a difference in type, but degree. There is a continuum, both formal and communicational, between the starting sentence, its potential explicatures, and its potential implicatures. In order to get to a truth-evaluable explicature, sometimes we will need to add something to its syntactico-semantic base, and sometimes we will also need to add other elements, whole premises, to get to an intended conversational implicature.

To make this clearer, we need to look at the reconstruction of implicatures (which is, just to briefly clarify, a post facto enterprise, not a real psychological interpretation) as a process of argument reconstruction. Looking at the reconstruction of conversational implicatures as a reconstruction of arguments gives epistemic strength to the belief that the listener creates based on indirectly conveyed content, it provides reasons for their conclusion. Walton and Macagno have argued that conversational implicatures should be analyzed as implicit arguments involving inference patterns that lead from a given premise to a conclusion (2013: 211). Consider the following example:

Oliver: Are you ready for the cinema?

Ana: I'm tired.

According to the systematization provided by Walton and Macagno, the dialogue can be explained as an argument from cause, that is, as a type of causal argument in which an event is associated with the cause that led to it. The general scheme is as follows: 
Major premise: In general, we can say that B will happen (or that it can happen) if A happens.

Minor premise: In this case, A happened (or it can happen).

Conclusion: Therefore, in this case B will happen (or can happen)

In the example given, Ana replies that she is tired instead of providing a direct answer to the question of whether she is ready to go to the movies. The purpose of her utterance is not to inform Oliver of her psychophysical condition, but to lead him to conclude from cause to effect. Fatigue is, at least in principle, incompatible with going to the movies: if someone is tired, then they should stay home. If someone stays at home, they cannot watch a movie at the cinema. Such a causal relationship is presented as a choice. Either A or B, not A, hence B.

Conversational implicatures can be considered as special cases of enthymemes, that is, instances of arguments with unstated premises or conclusions (see Blečić 2018). Enthymemes are reconstructed on the basis of their explicit elements using deductive, inductive or abductive forms of reasoning. The missing premises are generally taken to be assumptions that are needed to make the argument valid. Because of that, we should say that enthymemes are not the same as the reconstructed arguments based on them. We can say that the reconstructed argument represents the original one. The same goes for conversational implicatures. The reconstructed argument is not the same as the utterance, but it can be a representation of it and of its underlying logical structure. According to Gilbert (1991), incomplete arguments should be supplemented by assumptions that are convincing to the target audience and that fit into the position advocated by the speaker, of course, if there is no evidence to the contrary. Applying these ideas to conversational implicatures as reasonable arguments, we can say that the missing premises must be filled with assumptions that are plausible to the listener and that, at least seemingly, fit the speaker's attitude and the message he wants to convey. Arguments that we can say are made by implicatures, or that can be reconstructed on the basis of them, will always contain a dose of uncertainty, that is, they will not have the power of deduction, which does not allow exceptions. Yet such a thing is quite common in everyday reasoning, as noted by Mercier and Sperber (2017: 163 and 164). We can consider conversational implicatures as reason-giving arguments in which the speaker addresses a hearer who does not need to reply. In those cases, the speaker is not trying to convince the hearer to accept his position, as in the case of disputational arguments, but is explicitly stating a reason in support of the intended message. By grasping the intended message, the hearer intuitively accepts the reasons provided for it and can also reconstruct the argumentative path that leads from an explicit reason, qua premise, to the intended conclusion. A competent language speaker confronted with a statement that potentially carries a conversational implicature will attribute rationality to the sender of the mes- 
sage and begin the search for their communicative intent. Attributing this intention and the general knowledge of the speech community of which he is a part will be essential elements in his argumentative reconstruction of the speaker's message, and thus in justifying the belief he has created. Such a reconstruction will have an objective character: it does not depend solely on the speaker's intention, at least not if we do not view the speaker as a competent member of the speaking community who respects a whole range of established linguistic and social conventions. To be understood, conversational implicatures must have an argumentative basis. Here, the idea of a logical form, at least if broadened to encompass a looser, non-deductive sense, comes into play, providing good reasoning and communication patterns. Good reasoning shows patterns that can be schematically characterized by abstracting from the specific contents of the involved premises and conclusions, thus revealing a general form common to many other good conclusions. In the case of implicatures, such patterns will rarely be deductive, but they will nevertheless be crucial for their correct interpretation.

\section{Concluding remarks}

In order to assess the content of a sentence, we need to consider it contextually. Some sentences will need additional elements to convey a full proposition or, if they already carry a complete proposition, to modify it in order to suit what the speaker had in mind. This view of language is compatible with the idea that the bearers of logical form are not natural language sentences but their content in a particular context. Sentences have a logical form relative to interpretations because they have a logical form in virtue of the content they express. This idea reconciles what is sometimes seen as distinct areas of human interest-logic and pragmatics. Logic deals with formal principles of reasoning, and pragmatics with the use of language. How can we reconcile the two? Perhaps we should not start the exploration of the logic that governs communication at the syntactico-semantic level but the pragmatic level. We can assess the truth-value of a sentence only after we have explicated its content. Sometimes, we will be in the position to search for truth-values of the implicatum. We can always ask whether one implicates is true or false. But, before that, we will have to get to the right communicational content. To do that, we must look at conversational implicatures as implicit arguments. Implicatures are a rational communicational strategy, and rules are governing their communicatively cooperative production and reception. I suggest that these are the rules that govern the creation of good arguments, regardless of their status as deductive, inductive or abductive arguments. Of course, these kinds of arguments are governed by very different principles, but we need to consider them all if we want to address all possible pragmatic communicational possibilities.

We create meaningful connections between what is said and the 
environment (linguistic and non-linguistic), and to do so, these connections must be logically (in a broad sense) appropriate. Logical proprieties lead rational and meaningful communication; both implicit and explicit, making the notion of logical form useful for pragmatics.

\section{References}

Bach K. 2010. "Impliciture vs Explicature: What's the Difference?" In B. Soria and E. Romero (eds.). Explicit Communication. Palgrave Studies in Pragmatics, Language and Cognition. Palgrave Macmillan, London. https://doi.org/10.1057/9780230292352_8

Bach, K. 1994. "Conversational Impliciture." Mind and Language 9 (2): 124-162.

Bach, K. 2014. "Context Dependence.” In M. Garcia-Carpintero i M. Kolbel (ed.). The Bloomsbury Companion to the Philosophy of Language. Bloomsbury Publishing: 153-184.

Barwise, J. and Cooper, R. 1981. "Generalized Quantifiers and Natural Language." Linguistics and Philosophy 4(2): 159-219.

Blečić, M. 2018. "Do Conversational Implicatures Express Arguments?" Croatian Journal of Philosophy 11 (2): 335-350.

Carston, R. 2002. Thoughts and Utterances: The Pragmatics of Explicit Communication. Oxford: Wiley-Blackwell.

Chomsky, N. 1976. "Conditions on rules of grammar." Linguistic Analysis 2: 303-351.

Chomsky, N. 1995. The minimalist program. Cambridge: MIT Press.

Clark, R. 2011. "Generalized Quantifiers and Number Sense.” Philosophy Compass 6 (9): 611-621. doi:10.1111/j.1747-9991.2011.00419.x

Davidson, D. 1968. “On saying that." Synthese 19: 130-146.

Dutilh Novaes, C. 2012. Formal Languages in Logic: A Philosophical and Cognitive Analysis. Cambridge: Cambridge University Press.

Frege, G. 1967 [1879]. "Concept script, a formal language of pure thought modelled upon that of Arithmetic". In J. van Heijenoort (ed.). From Frege to Godel: A sourcebook in mathematical logic. Cambridge: Harvard University Press: 5-82.

Frege, G. 1980 [1891]. "Function and concept." In P. Geach and M. Black (eds.), Translations from the philosophical writings of Gottlob Frege. Oxford: Blackwell.

Gilbert, M. A. 1991. "The Enthymeme Buster: A Heuristic Procedure for Position Exploration in Dialogic Dispute.” Informal Logic 13 (3): 159166.

Iacona, A. 2018. Logical Form: Between Logic and Natural Language. Cham: Springer International Publishing.

Kaplan, D. 1977." Demonstratives.” In J. Perry, J. Almog and H. Wettstein (eds.). Themes from Kaplan. New York: Oxford University Press: 481-563.

Keenan, E. L. and Paperno. D. (eds.). 2012. Handbook of Quantifiers in Natural Language. Dordrecht: Springer Netherlands. doi:10.1007/97894-007 2681-9 
Levinson, S. C. 2000. Presumptive meanings: the theory of generalized conversational implicature. Cambridge: MIT Press.

Lewis, D. 1970. "General semantics.” In Philosophical papers (Vol. I, 189229). Oxford: Oxford University Press.

Macagno, F. and Walton, D. 2013. "Implicatures as Forms of Argument." In A. Capone et al. (eds.). Perspectives on Pragmatics and Philosophy. Berlin/New York: Springer: 203-224.

Mercier, H. and Sperber, D. 2017. The Enigma of Reason. Cambridge: Harvard University Press.

Montague, R. 1970. "Universal grammar." In Formal philosophy. New Haven: Yale University Press.

Montague, R. 1973. "The proper treatment of quantification in ordinary English.” In Formal philosophy. New Haven: Yale University Press.

Neale, S. 1993. "Logical form and LF." In C. Otero (ed.). Noam Chomsky: Critical assessments. London: Routledge: 788-838

Pietroski, P. 2016. "Logical Form." The Stanford Encyclopedia of Philosophy. Edward N. Zalta (ed.), URL = <https://plato.stanford.edu/archives/ spr2016/entries/logical-form/>.

Recanati, F. 2004. Literal Meaning. Cambridge: Cambridge University Press.

Russell, B. 1905. "On denoting." Mind 14: 479-493.

Russell, B. 1984. “Theory of knowledge.” In Collected papers (Vol. VI). London: Allen and Unwin.

Russell, B. 1998. The philosophy of logical atomism. La Salle: Open Court.

Soames, S. 1989. "Semantics and Semantic Competence." Philosophical Perspectives, Vol. 3, Philosophy of Mind and Action Theory: 575-596.

Sperber, D., and Wilson, D. 1986. Relevance. Oxford: Blackwell

Stanley, J. 2000. "Context and logical form." Linguistics and Philosophy 23: 391-434.

Westerståhl, D. 2019., "Generalized Quantifiers", The Stanford Encyclopedia of Philosophy (, Edward N. Zalta (ed.), URL = <https://plato.stanford.edu/archives/win2019/entries/generalized-quantifiers/>.

Wittgenstein, L. 1992. Tractatus logico-philosophicus. London: Routledge. Wittgenstein, L. 1993. "Some remarks on logical form". In J. Klagge and A. Nordmann (eds.). Philosophical occasions. Indianapolis: Hackett: 29-35 